\title{
Evaluation of the biocompatibility of calcium phosphate cement/PLGA microparticle composites
}

\author{
Dennis P. Link, ${ }_{1}^{1}$ Juliette van den Dolder, ${ }^{1}$ Jeroen J. J. P. van den Beucken, ${ }^{1}$ Vincent M. Cuijpers, ${ }^{1}$ \\ Joop G. C. Wolke, ${ }^{1}$ Antonios G. Mikos, ${ }^{2}$ John A. Jansen ${ }^{1}$ \\ ${ }^{1}$ Department of Periodontology and Biomaterials, Radboud University Nijmegen Medical Centre, \\ Nijmegen, The Netherlands \\ ${ }^{2}$ Department of Bioengineering, Rice University, Houston, Texas
}

Received 16 April 2007; revised 3 September 2007; accepted 18 October 2007

Published online 15 January 2008 in Wiley InterScience (www.interscience.wiley.com). DOI: 10.1002/jbm.a.31831

\begin{abstract}
In this study, the biocompatibility of a calcium phosphate $(\mathrm{CaP})$ cement incorporating poly (D,L-lactic- $\mathrm{CO}$ glycolic acid) (PLGA) microparticles was evaluated in a subcutaneous implantation model in rats. Short-term biocompatibility was assessed using pure $\mathrm{CaP}$ discs and $\mathrm{CaP}$ discs incorporating PLGA microparticles $(20 \% \mathrm{w} / \mathrm{w})$ with and without preincubation in water. Long-term biocompatibility was assessed using $\mathrm{CaP}$ discs incorporating varying amounts $(5,10$, or $20 \% \mathrm{w} / \mathrm{w})$ and diameter sizes (small, $0-$ $50 \mu \mathrm{m}$; medium, $51-100 \mu \mathrm{m}$, or large, $101-200 \mu \mathrm{m}$ ) of PLGA microparticles. The short-term biocompatibility results showed a mild tissue response for all implant formulations, irrespective of disc preincubation, during the early implantation periods up to 12 days. Quantitative histological evaluation revealed that the different implant formulations induced the formation of similar fibrous tissue capsules and interfaces. The results concerning long-term biocompatibility showed that all implants were surrounded by a thin connective tissue capsule ( $<10$ layers of fibro-
\end{abstract}

blasts). Additionally, no significant differences in capsule and interface scores were observed between the different implant formulations. The implants containing 20\% PLGA with medium- and large-sized microparticles showed fibrous tissue ingrowth throughout the implants, indicating PLGA degradation and interconnectivity of the pores. The results demonstrate that CaP/PLGA composites evoke a minimal inflammatory response. The implants containing 20\% PLGA with medium- and large-sized microparticles showed fibrous tissue ingrowth after 12- and 24-weeks indicating PLGA degradation and interconnectivity of the pores. Therefore, CaP/PLGA composites can be regarded as biocompatible biomaterials with potential for bone tissue engineering and advantageous possibilities of the microparticles regarding material porosity. (c) 2008 Wiley Periodicals, Inc. J Biomed Mater Res 87A: 760-769, 2008

Key words: CaP/PLGA cement; biocompatibility; interconnectivity

\section{INTRODUCTION}

The filling of bone defects resulting from trauma or surgical resection of tumors requires the availability of safe and reliable synthetic bone substitutes, since obtaining autologous bone is accompanied with the known disadvantages of donor site morbidity, increased operative time, and insufficient volumes. Calcium phosphate $(\mathrm{CaP})$ cements have been proven to be useful as bone substitutes at nonload bearing sites. ${ }^{1-4}$ Previous work on $\mathrm{CaP}$ cement has

Correspondence to: J. A. Jansen, DDS, PhD, Department of Periodontology and Biomaterials, PB 309, Radboud University, Nijmegen Medical Center, PO Box 9101, 6500 HB Nijmegen, The Netherlands; e-mail: J.Jansen@dent.umcn.nl

Contract grant sponsor: Ministry of Economic Affairs; contract grant number: NGT6205

(C) 2008 Wiley Periodicals, Inc. shown that if it consists of a mixture of powder and liquid, this $\mathrm{CaP}$ cement becomes injectable, and hence can be shaped perfectly according to the defect dimension in situ. ${ }^{5-8}$ Porosity can be created by incorporating degradable poly (D,L-lactic-co-glycolic acid) (PLGA) microparticles in the $\mathrm{CaP}$ cement to enhance tissue ingrowth in the $\mathrm{CaP}$ cement. ${ }^{9,10}$ PLGA microparticles will be hydrolyzed in vivo and as a consequence create microporosity. PLGA polymers are interesting due to degradation properties, which can be tailored by changing molecular weight, tacticity, and lactic to glycolic ratio. ${ }^{11}$ Although a previous study with various small-sized CaP/PLGA composite implants $(0,15,30$, or $50 \% \mathrm{w} / \mathrm{w}$ PLGA microparticles) showed an excellent bone response, ${ }^{12}$ additional studies to the biocompatibility of $\mathrm{CaP} /$ PLGA implants have to be performed to exclude that the incorporated PLGA microparticles evoke an inflammatory response during their degradation. In the design of such an experiment, it has to be 
TABLE I

Overview of the CaP/PLGA Disc Formulations

\begin{tabular}{llcc}
\hline & & \multicolumn{2}{c}{ PLGA } \\
\cline { 3 - 4 } & & \multicolumn{2}{c}{ Size } \\
& & Amount & $(\mu \mathrm{m})$ \\
\hline Short-term & CaP0 & - & $0-200$ \\
Biocompatibility & CaP0/PLGA & $20 \%$ & \\
$(2,4,8$ and 12 days) & CaP8 & - & \\
& CaP8/PLGA & $20 \%$ & \\
Long-term & CaP0/PLGA & $5 \%$ & $0-50$ \\
Biocompatibility & & & $51-100$ \\
$(12$ and 24 weeks) & & $10 \%$ & $0-200$ \\
& & & $51-100$ \\
& & & $101-200$ \\
& & $20 \%$ & $0-50$ \\
& & & $51-100$ \\
& & & $101-200$ \\
\hline
\end{tabular}

included that PLGA microparticle size can affect the foreign body reaction at the surface of the microparticles. ${ }^{13}$ Also, by varying the amounts and diameter sizes of PLGA microparticles a threshold for interconnectivity can be determined. Furthermore, these PLGA microparticles can be loaded with growth factors to stimulate bone formation and cement resorption in future applications. ${ }^{14,15}$

Also, the biocompatibility of CaP cement could be improved by preincubation in water. Previous research resulted in a better cellular response after preincubation in vitro, ${ }^{11}$ which could also have an effect on the final in vivo tissue response.

In view of the above mentioned, this study focused at the biocompatibility of $\mathrm{CaP}$ cement incorporating PLGA microparticles in a subcutaneous implantation model in rats. A subcutaneous location was proven before to be an appropriate location to evaluate the inflammatory reaction associated with $\mathrm{CaP}$ cement. $^{7}$ Short-term biocompatibility was assessed using $\mathrm{CaP}$ discs and $\mathrm{CaP}$ discs incorporating PLGA microparticles $(20 \% \mathrm{w} / \mathrm{w})$ with and without preincubation in water. Long-term biocompatibility was assessed using $\mathrm{CaP}$ discs incorporating various amounts $(5,10$, or $20 \% \mathrm{w} / \mathrm{w})$ and diameter sizes (small, 0-50 $\mu \mathrm{m}$; medium, $51-100 \mu \mathrm{m}$, or large, 101-200 $\mu \mathrm{m}$ ) of PLGA microparticles.

\section{MATERIALS AND METHODS}

\section{Substrates}

The CaP cement Calcibon ${ }^{\circledR}$ (Merck Biomaterial GmbH, Darmstadt, Germany) was used, which has a chemical composition of $61 \% \alpha$-TCP, $26 \% \mathrm{CaHPO}_{4}, 10 \% \mathrm{CaCO}_{3}$, and $3 \%$ PHA ( $\alpha$-TCP is alpha tri-calcium phosphate, PHA is precipitated hydroxyapatite). An aqueous solution of $1 \%$ $\mathrm{Na}_{2} \mathrm{HPO}_{4}$ was used as the liquid component. The used liquid/powder ratio was $0.35 \mathrm{~mL} / \mathrm{g}$. Before usage, the cement powder was sterilized by $\gamma$-radiation with $25 \mathrm{kGy}$ (Isotron B.V., Ede, The Netherlands) The cement liquid was filter-sterilized though a sterile $0.2-\mu \mathrm{m}$ filter.

\section{PLGA microparticles}

PLGA (Purasorb ${ }^{\circledR}$, Purac, Gorinchem, The Netherlands) with a molecular weight of $48 \mathrm{kDa}$ and a lactic to glycolic acid ratio of 50:50 was used. PLGA microparticles were prepared using a (water/oil/water) double emulsion solvent evaporation technique. The microparticles were produced by solving $1.0 \mathrm{~g}$ PLGA in $4 \mathrm{~mL}$ of dichloromethane (DCM) inside a glass tube. After dissolution, $500 \mu \mathrm{L}$ deionized water was added to this mixture and emulsified for $60 \mathrm{~s}$ on a vortexer. Subsequently, $6 \mathrm{~mL} 0.3 \%$ aqueous poly vinyl alcohol (PVA) solution was added and vortexed for another $60 \mathrm{~s}$ to produce the second emulsion. After vortexing, the content of the glass tube was transferred to a $1000 \mathrm{~mL}$ beaker and another $394 \mathrm{~mL}$ of $0.3 \%$ PVA was added slowly under continuous stirring. This was directly followed by adding $400 \mathrm{~mL}$ of a $2 \%$ isopropylic alcohol (IPA) solution. The suspension was stirred for $1 \mathrm{~h}$. After stirring, the microparticles were allowed to settle for $15 \mathrm{~min}$ and the solution was decanted. The microparticle suspension was centrifuged, and the clear solution at the top was decanted. Then $5 \mathrm{~mL}$ of deionized water was added, the microparticles were washed, centrifuged and the solution was aspirated. Finally, the microparticles were frozen, freeze-dried for $24 \mathrm{~h}$ and stored under argon at $-20^{\circ} \mathrm{C}$. For the short-term biocompatibility study, PLGA microparticles ranging from 5 to $200 \mu \mathrm{m}$ were used with an average diameter of $33 \mu \mathrm{m}$. For the long-term biocompatibility study, microparticles were sieved with a sieve shaker (Retsch GmbH, Haan, Germany) with 50, 100, and $200 \mu \mathrm{m}$ diameter sieves to obtain batches of small $(0-50 \mu \mathrm{m})$, medium $(51-100 \mu \mathrm{m})$, and large $(101-200 \mu \mathrm{m})$ PLGA microparticles.

\section{Pre-set sample preparation}

The discs were prepared by adding $350 \mu \mathrm{L}$ cement liquid $\left(1 \% \mathrm{w} / \mathrm{w}\right.$ aqueous solution of $\left.\mathrm{Na}_{2} \mathrm{HPO}_{4}\right)$ to a $1000 \mathrm{mg}$ $\mathrm{CaP}$ cement powder or CaP/PLGA mixture in a $2 \mathrm{~mL}$ syringe (Becton Dickinson, Alphen a/d Rijn, The Netherlands). The syringe was closed with an injection plunger and placed in a commercially available mechanical mixing apparatus as used for the preparation of dental amalgam
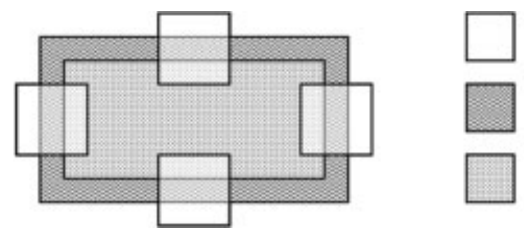

Area of evaluation

\section{Tissue}

Implant

Figure 1. Schematic drawing of a CaP/PLGA implant showing the four predetermined areas used in the histological evaluation. 
TABLE II

Histological Grading Scale for Soft-Tissue Implants

\begin{tabular}{|c|c|c|}
\hline Evaluation & Response & Score \\
\hline \multirow[t]{5}{*}{ Capsule quantitatively } & 1-4 fibroblasts & 4 \\
\hline & 5-9 fibroblasts & 3 \\
\hline & 10-30 fibroblasts & 2 \\
\hline & $>30$ fibroblasts & 1 \\
\hline & Not applicable & 0 \\
\hline \multirow[t]{5}{*}{ Capsule qualitatively } & $\begin{array}{l}\text { Capsule is fibrous, mature, not dense, resembling connective or fat tissue in the } \\
\text { noninjured regions }\end{array}$ & 4 \\
\hline & Capsule tissue is fibrous but immature, showing fibroblasts and little collagen & 3 \\
\hline & $\begin{array}{l}\text { Capsule tissue is granulous and dense, containing both fibroblasts and many } \\
\text { inflammatery cells }\end{array}$ & 2 \\
\hline & $\begin{array}{l}\text { Capsule consists of masses of inflammatory cells with little or no signs of connective } \\
\text { tissue organization }\end{array}$ & 1 \\
\hline & $\begin{array}{l}\text { Cannot be evaluated because of infection or other factors not necessarily related to the } \\
\text { material }\end{array}$ & 0 \\
\hline \multirow[t]{5}{*}{ Interface qualitatively } & $\begin{array}{l}\text { Fibroblasts contact the implant surface without the presence of macrophages or } \\
\text { leucocytes }\end{array}$ & 4 \\
\hline & Scattered focl of macrophages and leucocytes are present & 3 \\
\hline & One layer of macrophages and leucocytes are present & 2 \\
\hline & Multiple layers of macrophages and leucocytes present & 1 \\
\hline & $\begin{array}{l}\text { Cannot be evaluated because of infection or other factors not necessarily related to the } \\
\text { material }\end{array}$ & 0 \\
\hline
\end{tabular}

and dental cements (Silamat, Ivoclar Vivadent AG, Schaan, Liechtenstein). After mixing for $15 \mathrm{~s}$, the plunger was removed and the cement/composite was injected in teflon moulds to ensure a standardized shape of the specimens. The discs (2.4 $\mathrm{mm}$ height and $6 \mathrm{~mm}$ diameter) were removed from the moulds after setting of the cement at room temperature. Discs were used without $(\mathrm{CaP} 0)$ and with $(\mathrm{CaP} 8)$ preincubation in water $(8$ weeks immersion on a rotating plate with water, refreshing three times a week at room temperature).

\section{CaP/PLGA microparticle composites}

Various CaP/PLGA composites were created by adding PLGA microparticles to the $\mathrm{CaP}$ cement. $\mathrm{CaP}$ cement composites with 5,10 , or $20 \% \mathrm{w} / \mathrm{w}$ PLGA and small, medium, or large microparticle diameter sizes were prepared (Table I). The total porosity of the different CaP/PLGA composites was determined by correlating the weight of $\mathrm{CaP}$ discs with the weight of CaP/PLGA discs after placement of the samples in a furnace at $650^{\circ} \mathrm{C}$ for $2 \mathrm{~h}$ to remove the PLGA microparticles. ${ }^{16}$ Afterwards, samples were analyzed using microcomputed tomography $(\mu \mathrm{CT})$ (SkyScan 1172 high-resolution micro-CT, SkyScan, Kontich, Belgium). High-resolution scanning was performed at energy of $100 \mathrm{kV}$ and intensity of $98 \mu \mathrm{A}$. Cone beam reconstruction (version 2.15, Skyscan ${ }^{\mathbb{R}}$ ) was done. Also, the chemical composition of the samples was evaluated by crushing the samples with a mortar, until the discs were reduced to powder. The powder was then analyzed by using X-ray diffraction using a $\theta-2 \theta$ diffractometer (XRD, Philips PW3710, Eindhoven, the Netherlands) using a CuK $\alpha$-radiation of $1.5418 \AA$ wavelength. The positions and intensities of the XRD peaks were used to identify the underlying structure (phase) of the samples.

\section{Implantation}

Fifty-two male Wistar rats (100-120 g) were used for subcutaneous implantation. The rats received four implants each, two on each side of the vertical column. Short-term biocompatibility was assessed using four different implants $(n=6)$ with variation in implant composition and preincubation (Table I), and implantation periods of 2 , 4, 8, and 12 days. Long-term biocompatibility was assessed using nine different implants $(n=6)$ with variation in PLGA microparticle amount and size (Table I), and implantation periods of 12 and 24 weeks.

Surgery was performed under general inhalation anesthesia with a combination of isoflurane, nitrous oxide, and oxygen. For reasons of reliability, implant randomization was applied regarding location. To insert the implants, the

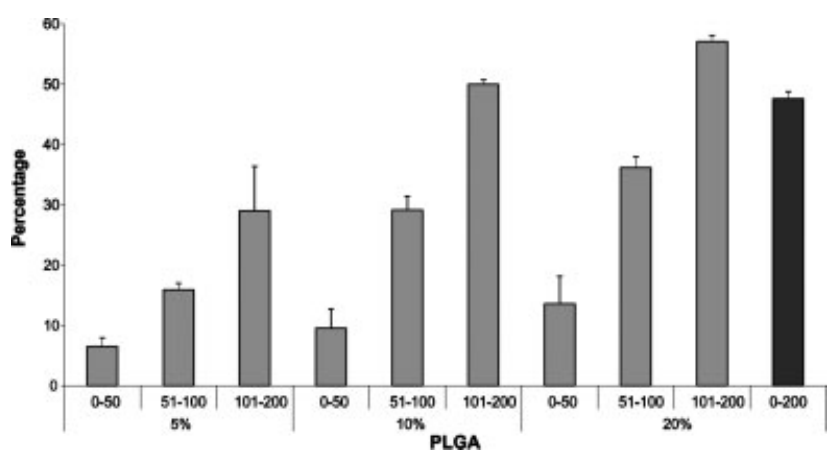

Figure 2. Microporosity (in \%) of the different implant formulations. The $20 \%$ PLGA $0-200 \mu \mathrm{m}$ sizes were used for the early implantation periods (short-term biocompatibility) (CaP0/PGLA and CaP8/PLGA). All other formulations were used for 12- and 24-weeks implantation (longterm biocompatibility). 


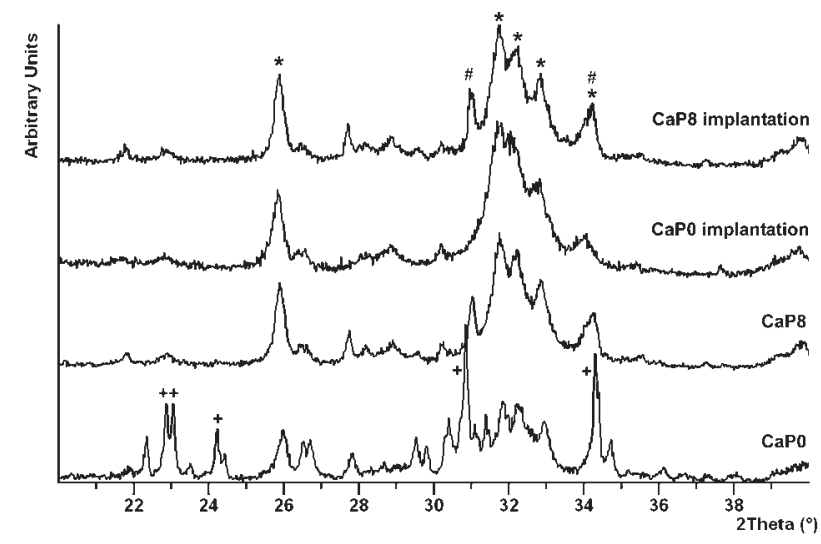

Figure 3. X-ray diffraction (XRD) patterns of the calcium phosphate cement discs. The XRD powder patterns of asprepared (CaP0) and preincubated discs (CaP8), both before and after subcutaneous implantation for 12 days. ${ }^{*}=$ apatite; $\#=\beta$-tri calcium phosphate $(\mathrm{TCP}) ;+=\alpha$-TCP).

animals were immobilized and placed in a ventral position. The back of the animals was shaved, washed, and disinfected with povidone-iodine. Subsequently, four small longitudinal incisions (two on each site of the vertebral column) were made. Lateral to each incision, a subcutaneous pocket was created using blunt dissection. After placement of the implants, the skin was closed using staples (Agraven ${ }^{\circledR}$, InstruVet BV, Cuijk, the Netherlands). At the end of each implantation period, the rats were sacrificed using $\mathrm{CO}_{2}$-suffication.

\section{Histology}

Implants with surrounding tissue were retrieved and prepared for histological evaluation. The samples were fixed in $4 \%$ formalin solution $(\mathrm{pH}=7.4)$, dehydrated in a graded series of ethanol and embedded in methylmethacrylate. Following polymerization, $10-\mu \mathrm{m}$ thick sections were prepared using a sawing microtome technique. ${ }^{17}$ The sections were stained with methylene blue and basic fuchsin and investigated with a light microscope to examine the amount of tissue inflammation or bone formation. The quantitative evaluation of the fibrous capsule was done in four predetermined fields using a histological grading scale for soft-tissue implants (Fig. 1 and Table II). ${ }^{18}$ The presented data represent the average of these four measurements.

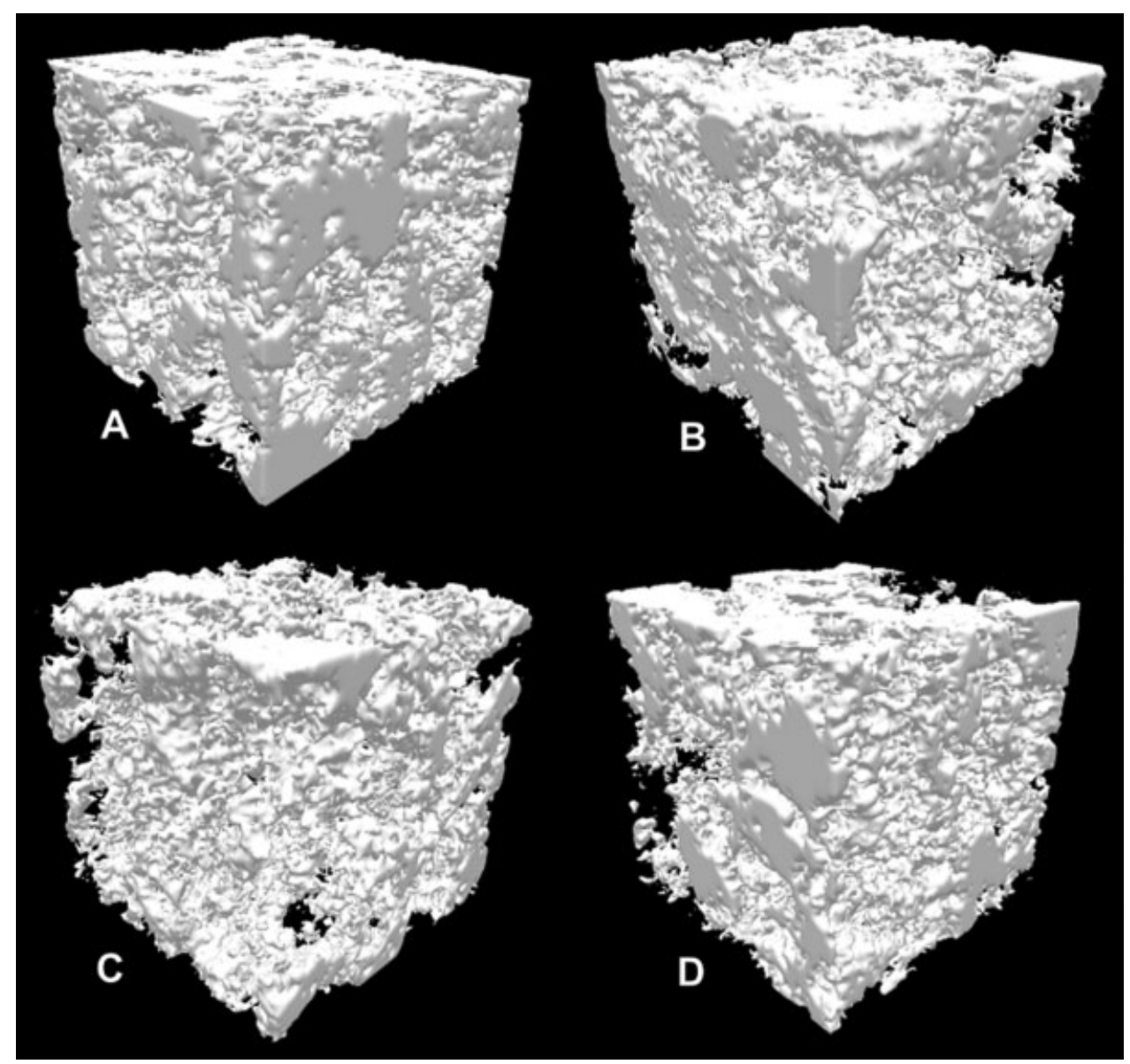

Figure 4. Microcomputed tomography ( $\mu \mathrm{CT}$ ) images of CaP implants containing 5\% (A), 10\% (B), 20\% (C) PLGA 101-200 $\mu \mathrm{m}$ sizes. Together with 20\% PLGA 0-200 $\mu \mathrm{m}$ sizes (D) used for the early implantation periods (short-term biocompatibility). PLGA microparticles appear as pores in the CaP cement. The size of each sample is $0.5 \times 0.5 \times 0.5 \mathrm{~mm}^{3}$. 

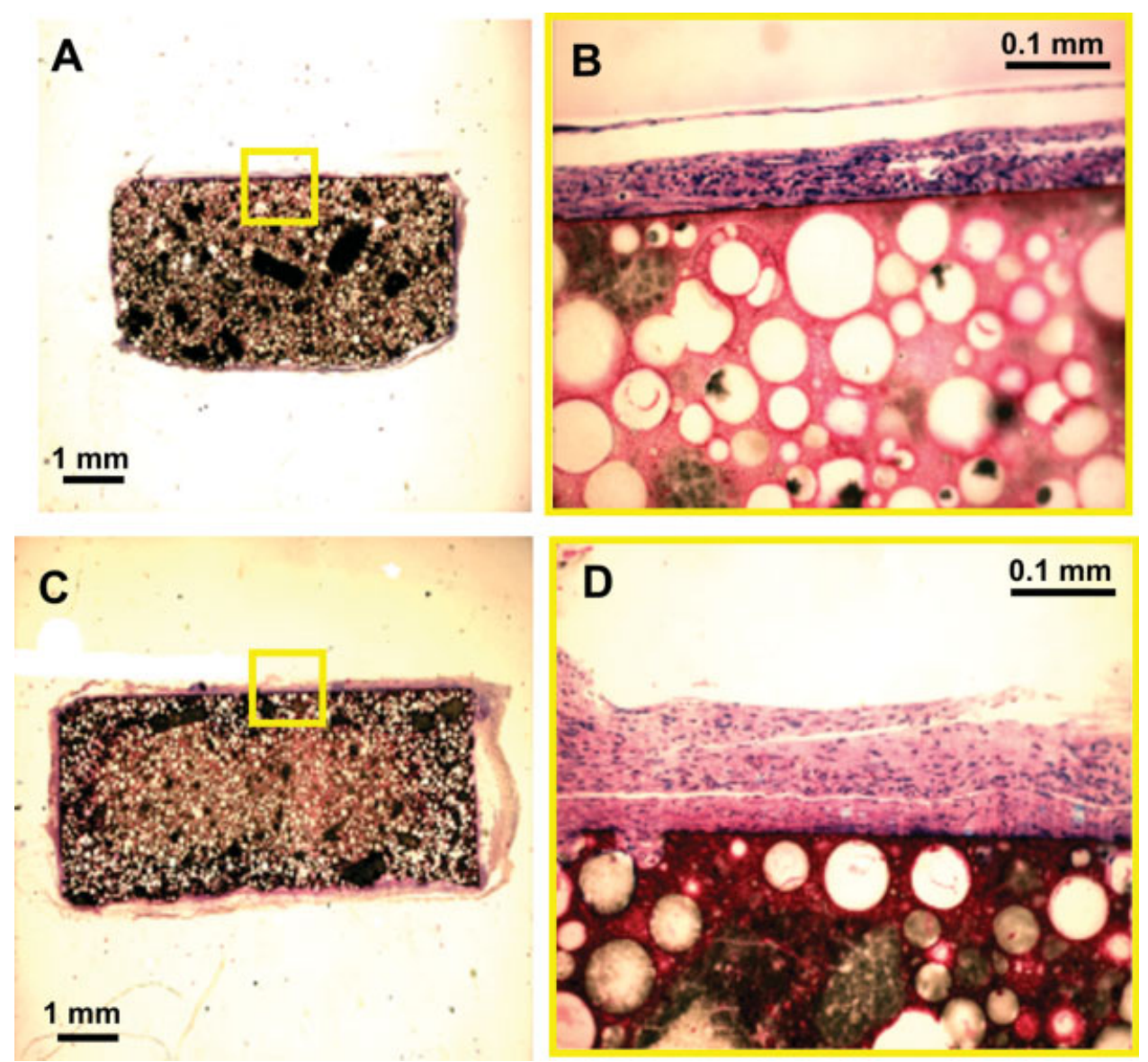

Figure 5. Histological sections of CaP implants containing 20\% PLGA microparticles after 4 days (A and B) and 12 days (C and D) of implantation. [Color figure can be viewed in the online issue, which is available at www.interscience.wiley.com.]

\section{Statistical analyses}

Statistical analyses were performed with GraphPad $^{\circledR}$ Instat 3.05 software (GraphPad Software, San Diego, CA) using a one-way analysis of variance (ANOVA) with a post-hoc Tukey multiple comparisons test.

\section{RESULTS}

\section{Implant characterization}

The microporosity of the various implant formulations varied between $6.5 \%$ and $57.1 \%$, showing lowest values for implants containing 5\% PLGA small-sized and highest values for implants containing 20\% PLGA large-sized microparticles (Fig. 2). XRD analysis demonstrated that the $\mathrm{CaP0}$ discs were mainly composed of $\alpha$-tri calcium phosphate $(\alpha-T C P)$. Preincubation of the discs for eight weeks in water (CaP8) resulted in the hydrolysis of $\alpha$-TCP into an apatitelike structure with some $\beta$-TCP. After implantation, the structure of the CaP8 samples remained the same, whereas the CaP0 samples underwent hydrolysis of $\alpha$-TCP into an apatite-like structure without $\beta$-TCP formation (Fig. 3). The incorporation of PLGA microparticles did not induce alterations of XRD patterns compared to pure $\mathrm{CaP}$ samples.

Microcomputed tomography $(\mu \mathrm{CT})$ indicated interconnectivity within all samples containing $20 \%$ (w/ w) PLGA, except for those with small diameter (0$50 \mu \mathrm{m}$ ) microparticles (Fig. 4).

\section{In vivo studies}

All 52 rats in this experiment remained in good health and did not show any wound complications. At retrieval, the 12- and 24-week implants were surrounded by a macroscopically visible fibrous capsule. All implants had retained their structural integrity, and no inflammatory signs or adverse tissue reactions were observed.

\section{Short-term biocompatibility}

Light microscopic analysis of the histological sections revealed that a fibrous tissue capsule developed around all implants in time. Furthermore, 

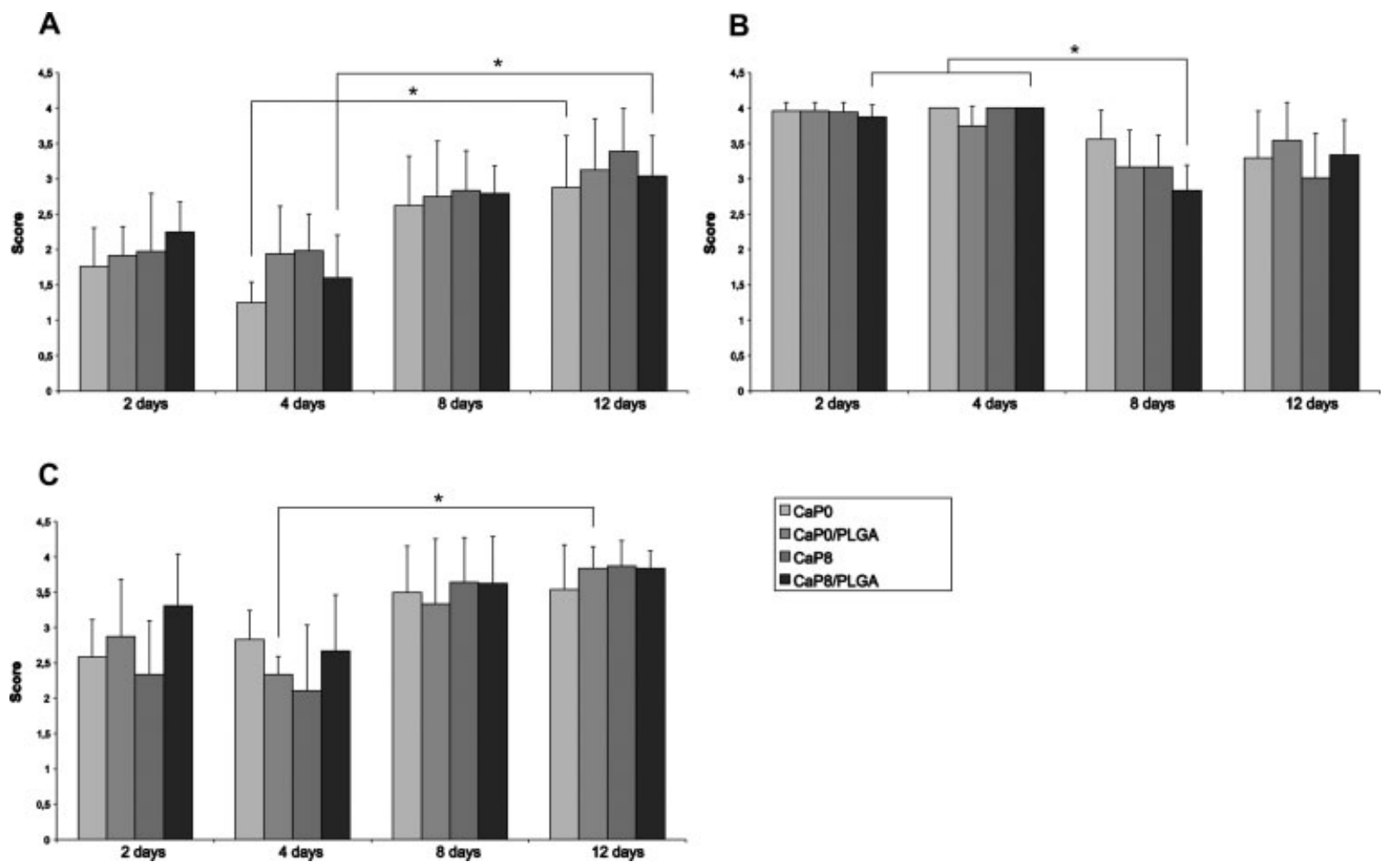

Figure 6. Histological evaluation of capsule quality (A), capsule quantity (B) and interface quality (C) of the short-term biocompatibility samples using the histological grading scale. Data shown represent mean \pm sd. Significant differences $(p<0.05)$ are indicated with an asterisk $\left(^{*}\right)$.

inflammatory cells were present during all implantation periods $(2,4,8$, and 12 days), but amounts were declining in time. No multinucleated cells were observed within any of the different implant formulations (CaP0, $\mathrm{CaP0} / \mathrm{PLGA}, \mathrm{CaP} 8$, and $\mathrm{CaP} 8 / \mathrm{PLGA})$. $\mathrm{CaP} / \mathrm{PLGA}$ cements, whether or not preincubated in water, did not contain fibrous tissue throughout the implants, but only concavities on the surface of the implants were filled with fibrous tissue.

After 2 days of implantation, inflammatory cells were observed in the implant vicinity without a connective tissue capsule around any of the implants. After 4 days [Fig. 5(A,B)], a thin connective tissue capsule had developed, containing inflammatory cells with some fibroblasts and a small amount of collagen bundles. After 8 days, the amount of collagen and number of fibroblasts increased in the thin connective tissue capsule and still few inflammatory cells were present. At 12 days [Fig. 5(C,D)], the thin fibrous capsule had not increased in size and the amount of fibroblasts and inflammatory cells appeared to be similar as for the 8-days implants.

Quantitative histological evaluation (Fig. 6) revealed that no significant differences in capsule and interface scores were present between the different formulations of implants (CaP0, CaP0/PLGA, $\mathrm{CaP8}$, and CaP8/PLGA) at individual time points. On the other hand, capsule quality scores of the
$\mathrm{CaP0}$ and CaP8/PLGA group were significantly different between 4 and 12 days, both showing the transformation of a granulous and dense capsule containing fibroblasts and inflammatory cells into a mature capsule resembling connective tissue [Fig. 6(A)]. Furthermore, capsule quantity scores of the CaP8/PLGA group between 4 and 8 days were significantly different, showing an increase in the number of fibroblast layers from 1 to 4 at day 4 to 5 to 9 fibroblast layers at day 8 [Fig. 6(B)]. Finally, capsule interface scores were significantly different between days 4 and 12 in the CaP0/PLGA group, where inflammatory cells contacting the surface of the implants were replaced by fibroblasts [Fig. 6(C)].

\section{Long-term biocompatibility}

All implant formulations (CaP with 5, 10 or $20 \%$ $\mathrm{w} / \mathrm{w}$ PLGA and small, medium, or large microparticle sizes) were surrounded by a connective tissue capsule containing fibroblasts, collagen bundles and few inflammatory cells after 12 weeks of implantation (Fig. 7). No multinucleated cells were observed within any of the different implant formulations. Similar observations were made after 24 weeks of implantation. Furthermore, only few inflammatory cells were present in the pores of the implants, 

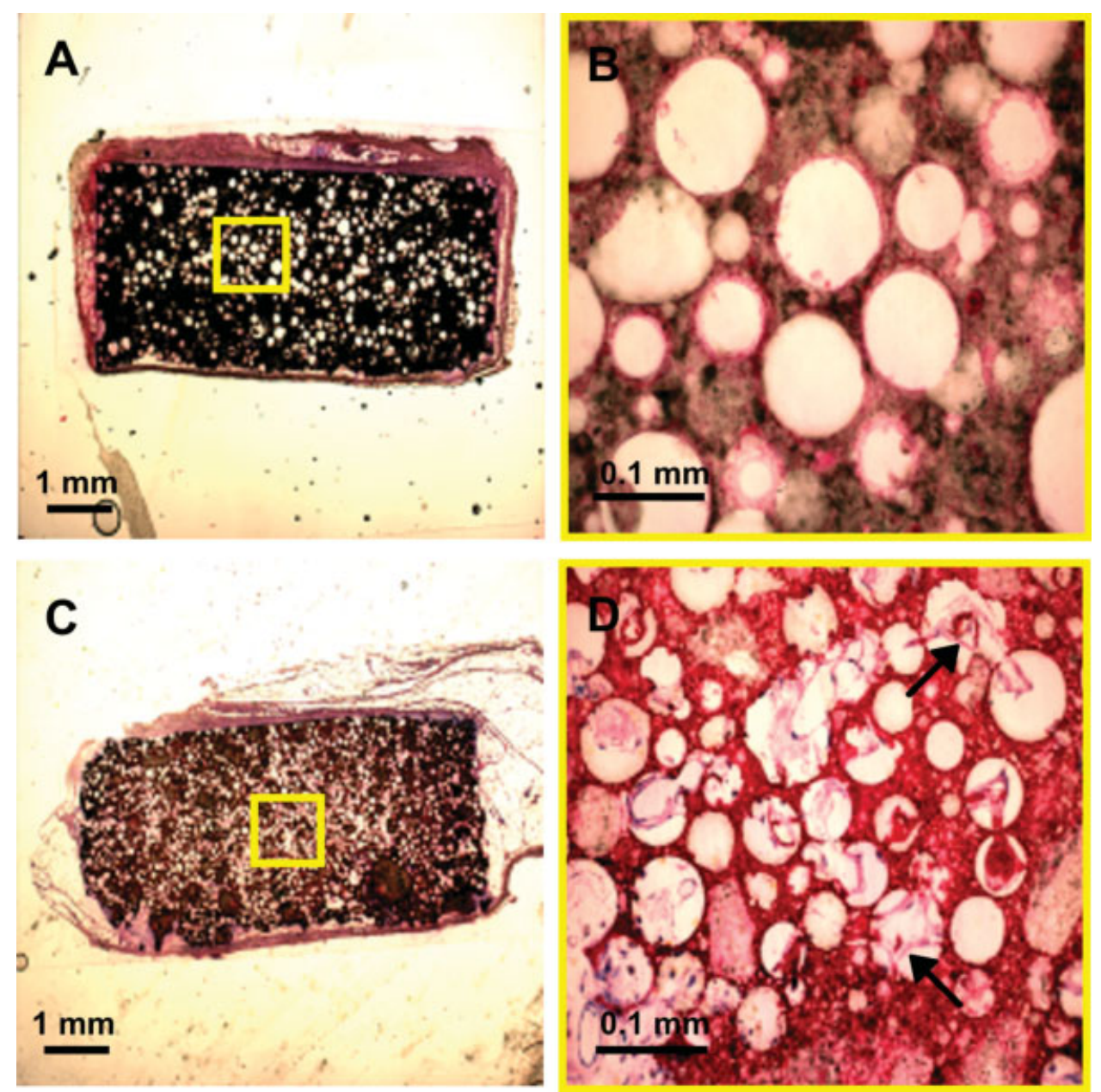

Figure 7. Histological sections of CaP implants containing 10\% PLGA 101-200 $\mu \mathrm{m}$ sizes (A and B) and 20\% PLGA 51-100 $\mu \mathrm{m}$ sizes $(C$ and $D)$ after 24 weeks of implantation. Arrows indicate fibrous tissue ingrowth. [Color figure can be viewed in the online issue, which is available at www.interscience.wiley.com.]

which were created after hydrolysis of PLGA microparticles. The implants containing 20\% PLGA with medium- and large-sized microparticles showed fibrous tissue ingrowth throughout the implants [Fig. $7(C, D)]$, indicating PLGA degradation and interconnectivity of the pores. This is in contrast to all 5\% and 10\% PLGA formulations, and 20\% PLGA formulations with small-sized microparticles, which only showed fibrous tissue ingrowth at the implant periphery. Quantitative histological evaluation revealed that no significant differences in capsule and interface scores were present between the different implant formulations (CaP with 5,10 , or $20 \% \mathrm{w} / \mathrm{w}$ PLGA and small, medium, or large microparticle sizes) at individual time points (Fig. 8).

\section{DISCUSSION}

This biocompatibility study was performed to exclude that the incorporated PLGA microparticles evoked an inflammatory response. Therefore, the short and long-term biocompatibility of CaP/PLGA formulations was examined using a subcutaneous implantation model in rats.

Physicochemical analysis demonstrated that due to implantation or preincubation in water, the $\alpha-\mathrm{TCP}$ component in the $\mathrm{CaP}$ cement undergoes hydrolysis resulting in transformation into an apatite-like structure. After implantation, $\mathrm{CaP}$ cement hydrolysis was more pronounced in preincubated samples compared to nonpreincubated samples. This might be due to a longer exposure time (8 weeks) of preincubated samples to water, the difference between body fluids and only water, or a combination of both.

Histological and histomorphometrical evaluation showed only a mild tissue response to any of the different CaP/PLGA composites formulations in the early implantation periods $(2,4,8$, and 12 days). No differences in vivo were observed between pure $\mathrm{CaP}$ cement and $\mathrm{CaP}$ cement incorporating PLGA microparticles, whether or not preincubated in water. Implant preincubation was based on the results of a previous in vitro study, ${ }^{13}$ which showed that without 

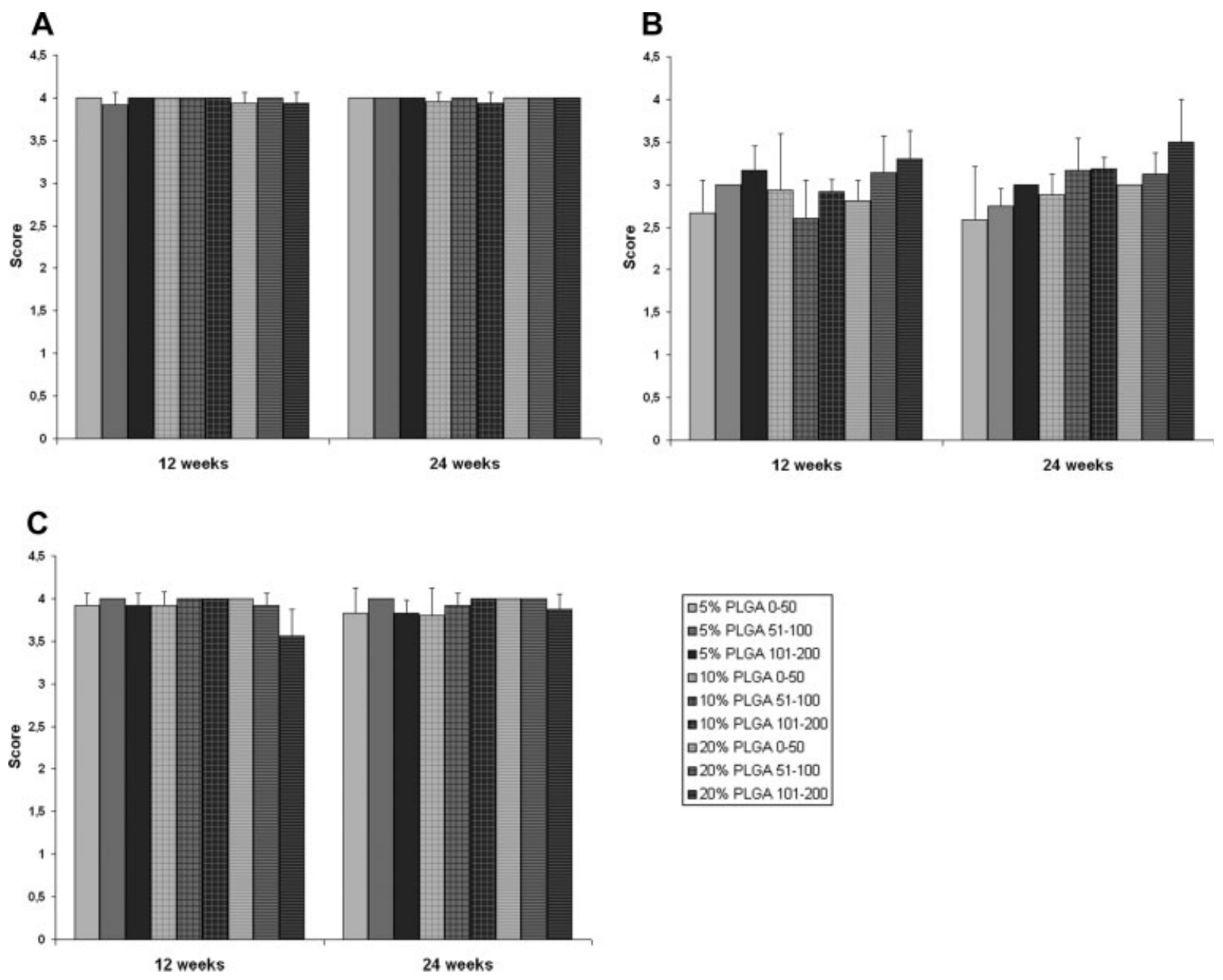

Figure 8. Histological evaluation of capsule quality (A), capsule quantity (B), and interface quality (C) of the long-term biocompatibility samples using the histological grading scale. Data shown represent mean \pm sd.

preincubation in water, $\mathrm{CaP}$ cement was not physicochemically stable. This resulted in the release of ionic species, which caused cell death. The preincubation of $\mathrm{CaP}$ cement resulted in the hydrolysis of $\alpha$ TCP into an apatite-like structure, which favored the biological response. However, the preincubated $\mathrm{CaP}$ cement still was not cytocompatible in vitro. ${ }^{13}$ Nevertheless, the in vivo results of the current study did not indicate a detrimental effect of formulations without preincubation on cells/tissues. Apparently, the capacity to buffer ionic species in vivo is higher than in in vitro experiments. Although PLGA is regarded as a nontoxic and biocompatible material, ${ }^{19}$ it is known that PLGA microparticles larger than $10 \mu \mathrm{m}$ in diameter can evoke a foreign body reaction at the surface of these microparticles. ${ }^{11,20}$ These data do not confirm the results of the current study, as no inflammatory response to PLGA microparticles was observed with various $(1-200 \mu \mathrm{m})$.

The microporosity in the CaP cement was created by incorporation and subsequent in vivo hydrolysis of PLGA microparticles. However, incorporation of microparticles is not a guarantee to achieve interconnectivity in the composites. In the present study, fibrous tissue ingrowth after 24 weeks throughout the implant indicated complete PLGA degradation and interconnectivity in the formulations containing $20 \%$ PLGA with medium and large microparticles. Recently, Habraken et al. showed that in vitro degradation of PLGA microparticles started after 6 weeks and was completed after 12 weeks. However, the reduction in molecular weight of the PLGA already started at day 0 and was $80 \%$ at 6 weeks when mass loss was visible. ${ }^{16}$ Therefore, the PLGA microparticles encapsulated in the $\mathrm{CaP}$ cement maintained their structure until 6 weeks, although molecular weight loss already commenced. In the current study, complete degradation of PLGA microparticles could only be evidenced by fibrous tissue ingrowth throughout the implants after 12 and 24 weeks.

Interestingly, in the implants containing $10 \% \mathrm{w} / \mathrm{w}$ PLGA with large microparticles, no fibrous tissue inside the implants was observed. This might indicate that within this CaP/PLGA formulation the 
micropores were not interconnected. However, the porosity of $50.1 \% \pm 0.7 \%$ in these implants was higher compared to the $36.2 \% \pm 1.9 \%$ porosity of in the implants with $20 \%$ PLGA with medium microparticles. This suggests that interconnectivity does not depend solely on larger particles, but also on smaller particles as a connecting agent. The most ideal might be a mixture of smaller and larger microparticles, where smaller particles can act as a connecting agent between the larger particles to create an interconnected network. The interconnectivity in the composites with 20\% PLGA with medium and large microparticles corroborates other studies indicating the necessity of pores of at least $50 \mu \mathrm{m}$ to obtain optimal porosity of porous ceramics. ${ }^{21}$ Microcomputed tomography also indicated interconnectivity between the samples of $20 \%$ PLGA with medium and large sized microparticles. By applying a threshold to the images, the $\mathrm{CaP}$ cement was extracted form the original image. Because of reasons of arbitrary threshold as a result of alternating ranges and intensities of individual sample grey scales, $\mu \mathrm{CT}$ was not applicable for quantification of porosity and interconnectivity. ${ }^{22,23}$ Therefore, $\mu \mathrm{CT}$ was only used to visualize the appearance of the samples.

Remarkably, a study by Ruhé et al. indicated that $\mathrm{CaP}$ cement possesses a certain degree of intrinsic osteoinductive properties, as they found mineralized extracellular matrix in pores after PLGA degradation. ${ }^{10}$ However, that study consisted of smaller $\mathrm{CaP} /$ PLGA implants $(2.0 \mathrm{~mm}$ height and $3.5 \mathrm{~mm}$ diameter) together with larger PLGA microparticles $(73 \pm 27 \mu \mathrm{m})$ combined with $\mathrm{CO}_{2}$ induced macropores, which together gave a heterogeneous distribution of macropores. Although, the current study was not designed to examine possible osteoinductivity of $\mathrm{CaP}$ cement, none of the composite formulations showed any formation of bone upon subcutaneous implantation. However, these observations do not exclude osteoinductive properties of $\mathrm{CaP}$ cement, since factors like species, implant location, and implant size are known to influence the formation of bone tissue at ectopic sites. ${ }^{24,25}$

\section{CONCLUSIONS}

The results of the present study demonstrate that CaP/PLGA composites evoke a minimal inflammatory response. The implants containing 20\% PLGA with medium- and large-sized microparticles showed fibrous tissue ingrowth throughout the implants after 12 and 24 weeks indicating PLGA degradation and interconnectivity of the pores. Therefore, CaP/PLGA composites can be regarded as biocompatible biomaterials with potential for bone tissue engineering and advantageous possibilities of the microparticles regarding material porosity.

We would like to thank the Dutch Technology Foundation (STW) applied science division of NWO.

\section{References}

1. del Real RP, Ooms E, Wolke JG, Vallet-Regi M, Jansen JA In vivo bone response to porous calcium phosphate cement. J Biomed Mater Res A 2003;65:30-36.

2. Ooms EM, Wolke JG, van der Waerden JP, Jansen JA. Trabecular bone response to injectable calcium phosphate (Ca-P) cement. J Biomed Mater Res 2002;61:9-18.

3. Ooms EM, Wolke JG, van de Heuvel MT, Jeschke B, Jansen JA. Histological evaluation of the bone response to calcium phosphate cement implanted in cortical bone. Biomaterials 2003;24:989-1000.

4. Hamadouche M, Sedel L. Ceramics in orthopaedics. J Bone Joint Surg Br 2000;82:1095-1099.

5. Comuzzi L, Ooms E, Jansen JA. Injectable calcium phosphate cement as a filler for bone defects around oral implants: An experimental study in goats. Clin Oral Implants Res 2002;13: 304-311.

6. Ooms EM, Wolke JG, van der Waerden JP, Jansen JA. Use of injectable calcium-phosphate cement for the fixation of titanium implants: An experimental study in goats. J Biomed Mater Res B 2003;66:447-456.

7. Jansen J, Ooms E, Verdonschot N, Wolke J. Injectable calcium phosphate cement for bone repair and implant fixation. Orthop Clin North Am 2005;36:89-95.

8. Horstmann WG, Verheyen CC, Leemans R. An injectable calcium phosphate cement as a bone-graft substitute in the treatment of displaced lateral tibial plateau fractures. Injury 2003;34:141-144.

9. Link DP, van den Dolder J, Jurgens WJ, Wolke JG, Jansen JA. Mechanical evaluation of implanted calcium phosphate cement incorporated with PLGA microparticles. Biomaterials 2006;27:4941-4947.

10. Ruhe PQ, Hedberg-Dirk EL, Padron NT, Spauwen PH, Jansen JA, Mikos AG. Porous poly(DL-lactic-co-glycolic acid)/calcium phosphate cement composite for reconstruction of bone defects. Tissue Eng 2006;12:789-800.

11. Shive MS, Anderson JM. Biodegradation and biocompatibility of PLA and PLGA microspheres. Adv Drug Deliv Rev 1997; 28:5-24.

12. Ruhe PQ, Hedberg EL, Padron NT, Spauwen PH, Jansen JA, Mikos AG. Biocompatibility and degradation of poly(DL-lactic-co-glycolic acid)/calcium phosphate cement composites. J Biomed Mater Res A 2005;74:533-544.

13. Link DP, van den Dolder J, Wolke JG, Jansen JA. The cytocompatibility and early osteogenic characteristics of an injectable calcium phosphate cement. Tissue Eng 2007;13: 493-500.

14. Ruhe PQ, Hedberg EL, Padron NT, Spauwen PH, Jansen JA, Mikos AG. rhBMP-2 release from injectable poly(DL-lactic-coglycolic acid)/calcium-phosphate cement composites. J Bone Joint Surg Am A 2003;85 (Suppl 3):75-81.

15. Ruhe PQ, Boerman OC, Russel FG, Spauwen PH, Mikos AG, Jansen JA. Controlled release of rhBMP-2 loaded poly(DL-lactic-co-glycolic acid)/calcium phosphate cement composites in vivo. J Control Release 2005;106:162-171.

16. Habraken WJ, Wolke JG, Mikos AG, Jansen JA. Injectable PLGA microsphere/calcium phosphate cements: Physical properties and degradation characteristics. J Biomater Sci Polym Ed 2006;17:1057-1074. 
17. van der Lubbe HB, Klein CP, de Groot K. A simple method for preparing thin (10 microM) histological sections of undecalcified plastic embedded bone with implants. Stain Technol 1988;63:171-176.

18. Jansen JA, Dhert WJ, van der Waerden JP, von Recum AF. Semi-quantitative and qualitative histologic analysis method for the evaluation of implant biocompatibility. J Invest Surg 1994;7:123-134.

19. Ishaug-Riley SL, Crane-Kruger GM, Yaszemski MJ, Mikos AG. Three-dimensional culture of rat calvarial osteoblasts in porous biodegradable polymers. Biomaterials 1998;19:1405-1412.

20. Peter SJ, Miller MJ, Yasko AW, Yaszemski MJ, Mikos AG. Polymer concepts in tissue engineering. J Biomed Mater Res 1998;43:422-427.

21. Bohner M, Baumgart F. Theoretical model to determine the effects of geometrical factors on the resorption of calcium phosphate bone substitutes. Biomaterials 2004;25:3569-3582.
22. Hiu-Yan Y, Ling Q, Kwong-Man L, Ming Z, Kwok-Sui L, Chun-yiu CJ. Novel approach for quantification of porosity for biomaterial implants using microcomputed tomography (microCT). J Biomed Mater Res B Appl Biomater 2005;75:234242.

23. Jones AC, Arns CH, Sheppard AP, Hutmacher DW, Milthorpe BK, Knackstedt MA. Assessment of bone ingrowth into porous biomaterials using MICRO-CT. Biomaterials 2007;28: 2491-2504.

24. Habibovic P, Yuan $\mathrm{H}$, van der Valk CM, Meijer G, van Blitterswijk CA, de Groot K. 3D microenvironment as essential element for osteoinduction by biomaterials. Biomaterials 2005; 26:3565-3575.

25. Habibovic P, Sees TM, van den Doel MA, van Blitterswijk CA, de Groot K. Osteoinduction by biomaterials-physicochemical and structural influences. J Biomed Mater Res A 2006;77:747-762. 